OPEN ACCESS

Edited by:

Claudio Longobardi,

Università degli Studi di Torino, Italy

Reviewed by:

Tomas Jungert,

Lund University, Sweden

Ratna Nandakumar,

University of Delaware, United States

*Correspondence:

Prathiba Natesan

prathiba.natesan@unt.edu

†These authors have contributed equally to this work.

Specialty section:

This article was submitted to

Educational Psychology,

a section of the journal

Frontiers in Education

Received: 25 February 2018

Accepted: 12 June 2018

Published: 29 June 2018

Citation:

Natesan P, Mitchell ME and Glover RJ (2018) Early Predictors of Child's Bully and Victim Statuses: A Longitudinal Investigation Using Parent, Teacher, and Student Reports From National

Data. Front. Educ. 3:48.

doi: 10.3389/feduc.2018.00048

\section{Early Predictors of Child's Bully and Victim Statuses: A Longitudinal Investigation Using Parent, Teacher, and Student Reports From National Data}

\author{
Prathiba Natesan ${ }^{\star \dagger}$, Mary E. Mitchell ${ }^{\dagger}$ and Rebecca J. Glover \\ Educational Psychology, University of North Texas, Denton, TX, United States
}

Although bullying is known to have detrimental effects, less is known regarding how these bullies and victims develop within the contexts of their homes and schools, and how early childhood behaviors can predict later bullying/victimization statuses. Parent, teacher, and student reports from the Early Childhood Longitudinal Study-Kindergarten (ECLS-K) 1998-1999 cohort $(N=11,715)$ representing a nationwide sample of children, were utilized to predict child's bully and victim status in eighth grade (age 13-14) using data from seven collection points. Results indicated child characteristics from the earliest time points identified children at risk for becoming both bullies and victims, although familial characteristics were only able to predict bully status. Identifying these characteristics provides opportunities for early intervention in children's lives, potentially preventing negative effects of bullying and victimization on academic, social, and emotional functioning. Implications for future research, including special considerations for individuals with internalizing behaviors, are discussed.

Keywords: bullying, predictors of bullying, externalizing problem behaviors, internalizing problem behaviors, ECLS

\section{INTRODUCTION}

Bullying and the victimization of peers in school are not new phenomena. In it's most recent report, the National Center for Educational Statistics (NCES) found that $20.8 \%$ of 12 -18-year-olds in the U.S. reported being bullied at school (U.S. Department of Education Institute of Education Science National Center for Educational Statistics, 2016). This indicates that just over one-fifth of all American high school students have been victimized, despite widespread efforts and resources haveing been devoted to anti-bullying campaigns (Pacer Center, 2016; Stomp Out Bullying, 2016), and anti-bullying legislation in all 50 states (Temkin, 2015). Although these national efforts have been made to stop bullying, fewer interventions have aimed to prevent bullies from developing in the first place. Lereya et al. (2015a) argue peer victimization during childhood may have more long-term effects on the mental health of its victims than does parental maltreatment or abuse. In fact, children identified as victims were at a greater risk for depression, suicidal ideation, suicidal behavior, and self-harm in adulthood. This risk was greater than for those adults who had been subject to parental abuse or neglect during childhood. This indicates that early intervention may be key to supporting healthy socioemotional development across childhood. 


\section{Home Environment}

Lereya et al. (2013) found that a child's home environment was the single best predictor of future victimization. Children who reported their parents to engage in abusive, neglectful, or maladaptive parenting were most likely to be victimized, while children who reported positive communication with and high levels of support and guidance from their parent(s) were less likely to be involved. Similarly, Espelage et al. (2018) reported that both positive and negative family functioning were able to predict the developmental trajectory of bullying behaviors from middle to high school. Other studies have also reported that positive familial relationships appear to serve as a protective factor against participation in bullying (Keelan et al., 2014; Kretschmer et al., 2016; Doty et al., 2017). While these reports provide evidence that children's home lives may contribute to participation in the bully-victim dynamic, other studies have implicated mental health problems in the process, as well.

Multiple studies (Veenstra et al., 2005; Kozasa et al., 2017) have found that the children of individuals diagnosed with internalizing disorders were more likely to also report being victims of bullies, while other research (Harold et al., 1997; Cui et al., 2007; Braithwait et al., 2015) have reported a reciprocal relationship between child behavioral disorders and marital conflict. Outside of psychopathy, others have found that victim status was related to increased levels of family conflict and negative expressiveness throughout the family (Mohr, 2006). Georgiou (2009) discovered a similar relationship between maternal depression and bully status, supposing that the presence of maternal depression may lead to more coercive methods of punishment to gain compliance.

Beyond family communication, parental involvement in children's lives has been associated with a reduced risk for involvement in bullying (Flouri and Buchanan, 2003; Dehue et al., 2012). Haynie et al. (2001) reported that middle school students identified as both bullies and victims reported lower levels of parental attention, help, and praise than their uninvolved counterparts, although victims' parents reported providing the highest levels of support across all categories. In addition to parents' presence, the quality of the parents' interactions with the child(ren) may also play a role in the development of bullies and victims.

Several studies have reported that the parents of bullies are more likely to use authoritarian or permissive parenting styles (Baldry and Farrington, 2000; Charalampous et al., 2018), use more forms of physical punishment (Gomez-Ortiz et al., 2016), and develop more insecure attachment styles with their children (Elliot and Cornell, 2009) relative to the parents of victims and uninvolved students. Although high levels of parentchild conflict and bully status are correlated (Georgiou and Stavrinides, 2013), Pepler et al. (2008) reported that the same bullies who reported high levels of conflict with their parents also reported high levels of trust for those same parents. While these preadolescents may argue and fight often with their parents, it also appears that they are receiving some forms of parental support.
While some research has demonstrated a lower level of family functioning for bullies, other studies have indicated that the opposite may be true for victims. While some studies have reported similar authoritarian or permissive parenting styles for victims (Charalampous et al., 2018; Georgiou et al., 2018), other studies have found that the families of victims reported higher levels of family functioning and involvement vs. their bully counterparts, although those levels were still lower than the levels reported by uninvolved children (Stevens et al., 2002; Cassidy, 2009). These conflicting results may indicate that victims do not share similar home characteristics like their bully counterparts, making their identification all the more difficult.

\section{Internalizing and Externalizing Behaviors}

Eastman et al. (2018) found that more frequent victimization was associated with higher levels of internalizing behaviors in a sample of adolescents, while several other studies have established a link between victim status and internalizing disorders (Hawker and Boulton, 2000; Haynie et al., 2001; Mohr, 2006; Holt and Espelage, 2007). A meta-analysis by Cook et al. (2010) reported similar results when reporting that while both bullies and victims report behavioral issues, victims were more likely to report internalizing disorders and bullies were more likely to report externalizing disorders. Further highlighting these similarities, Haynie et al. (2001) found both bullies and victims possess lower levels of self-control relative to uninvolved children. These results seem to indicate that the children most at risk for becoming bullies and victims are those who are also at risk for mental health issues.

\section{Discrepancies Between Multiple Sources}

The results of the Stevens et al. (2002) study, much like the work from Haynie et al. (2001), found that parents reported higher rates of cohesion and expressiveness within the family than their children. Additional studies (Waasdorp et al., 2011; Ahn et al., 2013) have also discovered discrepancies between teachers' and students' reports of bullying, while other research (Stockdale et al., 2002; Waasdorp and Bradshaw, 2009) has also found disconnects between parent and child reports. A recent study by Hwang et al. (2017) even found that discrepancies between peer and self-report were related to higher levels of reported behavioral problems later in the year. These discrepancies between teacher, parent, and student reports of bullying and the home environment indicate that it is vitally important to consider the input of multiple sources of information when investigating bullying and victimization, as each source may view relationships and environments in different ways.

\section{Gap in the Literature}

In sum, existing studies have considered only two sources of information (i.e., teacher and student, parent, and child), which means we can understand the child's behaviors from only two perspectives and settings. None of these studies have tracked children's behaviors from as early as kindergarten to predict their bully or victim statuses in eighth grade. Most of the studies used univariate general linear models (e.g., multiple regression, ANCOVA) on measured variables. 
Identifying relationships across factors, that is, the underlying constructs which influence the measured variables gives a deeper understanding and a better representation of the complexity of these phenomena. Finally, the results from analysis of large-scale, nationally representative longitudinal sample are generalizable, whereas very few existing studies use such extensive samples.

\section{Purpose and Significance}

The purpose of the present study was to predict a child's bully and victim statuses in eighth grade using longitudinal reports by teachers, parents, and the children themselves of the child's externalizing and internalizing behaviors, and parent reports of home environments regarding their marital lives and parental responsiveness. The hypothesis governing the current analyses is that teacher, parent, and student reports of externalizing and internalizing behaviors, as well as parent reports of marital and home characteristics will be able to predict bully and victim status by Grade 8, such that teachers, parents, and students will report higher levels of externalizing behaviors, higher levels of marital dissatisfaction, and lower levels of parental responsiveness for bullies, while teachers, parents, and students will report higher levels of internalizing behaviors for victims. Data from the Early Childhood Longitudinal Study, Kindergarten Class 19981999 (ECLS-K) were analyzed using predictor variables collected as early as kindergarten. The ECLS-K data are a nationwide, longitudinal data collected across three sets of sources (teachers, parents, and children) across 7 time-periods. The data were collected from when the child began kindergarten to when the child was in eighth grade. Consequently, data from the ECLS-K were fitted to a model that predicted a child's bully and victim status by the 8th grade year using reports from parents, teachers, and the students themselves across kindergarten to fifth grade. Thus, data from multiple sources were used to predict future victim and bully statuses which strengthens the findings of the present study.

Using large-scale, nationally representative data such as the ECLS-K helps identify the general trends nationwide. This is especially important for the ECLS-K 1998-1999 data because participants who were studied in this cohort are now serving as young parents, teachers, and the current work force. Understanding and taking lessons from their own behaviors can help implement positive interventions in this next generation of children's lives.

Unlike other studies (e.g., Lereya et al., 2015b) that used extensive mental health evaluations and family interviews, the instruments used to measure the ECLS-K data are simpler and are more readily available to school personnel. The questions presented to the teachers and parents in the ECLS-K are simple but previously validated assessments of various child behaviors. Therefore, the use of the ECLS-K data might enable those with the most access to these children (i.e., teachers and parents) to recognize risk factors earlier in development. They can intervene before the negative effects of bullying and victimization can impact the children's academic, social, and emotional functioning. Because the goal of bullying research is to help end these behaviors in classrooms and neighborhoods, the use of risk factors more immediately recognizable to teachers and parents is paramount to enabling prevention efforts.

\section{METHODS}

\section{Sample}

Data for the present study was obtained from the ECLS-K 1998-1999, collected by the U.S. Department of Education's National Center for Education Statistics (NCES). The ECLS-K is a nationally representative sample of school children $(n=21,260)$, collected via multi-stage probability design, who entered both public and private kindergarten programs in the Fall of 1998. The sample for this study $(n=11,715)$ was comprised only of those participants for whom data was available from the child, the parent, and the teacher across the entire 9 years of data collection, concluding in Spring, 2007.

Information was collected at each time point via interviews and questionnaires given to the parents, teachers, and students and completed by hand by a surveyer. The present study used measures collected in the Fall and Spring semesters of kindergarten and 1st grade, as well as the Spring semesters of 3rd, 5 th, and 8th grades regarding demographic information, reports of children's behavior, and measures of the home environment. This particular data set was chosen specifically for its wealth of sources as well as the longitudinal scope of data collection over 9 years. The time points are indicated thus in the present study: Fall kindergarten (T1), spring kindergarten (T2), fall 1st grade (T3), spring 1 st grade (T4), and spring 3rd (T5), 5th (T6) and 8th (T7) grades.

\section{Measures}

\section{Children's Social Skills and Behavior}

Teachers' ratings of children's externalizing and internalizing behaviors in the classroom were collected during the Fall and Spring of the kindergarten year, as well as the Spring of 1st, 3rd, and 5th grades. Children's self-evaluations were also collected in the Spring of 5 and 8th grades via questionnaires related to the child's internalizing and externalizing behaviors, as well as feelings of sadness, loneliness, and locus of control. The data collected at these times points were utilized to develop a holistic view of the children's classroom and school behavior throughout childhood from multiple sources. The use of multiple sources was intended to help overcome issues reported in previous research. These include children being less likely to admit bullying behavior vs. peer nomination (Elliot and Cornell, 2009), the agreement between child and peer reports varying with age and gender (Ladd and Kochenderfer-Ladd, 2002).

In addition to its own questions, the ECLS study used an adaptation of the Social Skills Rating System (SSRS; Gersham and Elliot, 1990) to assess children's social skills and functioning in the Fall and Spring semesters of kindergarten and 1st grade, as well as the Spring semesters of the 3rd, 5th, and 8th grade years. This adaptation, known as the Social Rating System (SRS), gathered child, parent, and teacher perceptions of the children's interactions with peers at each time point, including direct questions regarding bullying behaviors. The present study also analyzed data collected from parents in the Fall and Spring 
of kindergarten and Spring of 1st grade to measure parents' perceptions of their child's use of social skills and their feelings of sadness or loneliness.

\section{Home Environment}

Information regarding the children's home environments, including the parents marital or romantic relationship and parent-child interactions, was gathered via parent interviews at several time points throughout the ECLS-K. These data included the quality of interactions between parental figures and between those figures and the child. The factors included: (a) marital aggression (PAggcomm), or how the parental figures managed conflict within the marital relationship (e.g., argue heatedly or shout, criticize each other, argue in front of the children) (b) marital passive communication (PPasscomm), or the level of communication between parents (e.g., criticize each other, discuss calmly, stop speaking), and (c) marital dissatisfaction (PMardiss), or the dissatisfaction the reporting parent felt in his or her relationship (e.g., my partner listens to me, I trust my partner to be faithful, I view our relationship as lifelong). In addition to parent-parent relations, other questions gauged the level of emotional responsiveness provided by the parents expressed as the number of times child was praised, shown affection, or told he or she was loved. All items and their respective scales of measurement are given in Table $\mathbf{1}$.

\section{Procedures}

Data from parents, teachers, and students across 6 time-points were analyzed: Fall 1998 (T1), Spring 1999 (T2), Spring 2000 (T4), Spring 2001 (T5), Spring 2003 (T6), Spring 2005 (T7), and Spring 2007 (T8). Data from Fall 2000 (T3) were deleted from the model because all variables of interest from T3 were highly correlated with those from $\mathrm{T} 2$ and resulted in multicollinearity $(r>0.85)$. Weighting procedure was applied for the longitudinal data as per the ECLS-K manual. No particular patterns were found in the missing data. Therefore, missing responses were imputed by matching cases using LISREL 8.8 (Jöreskog and Sörbom, 2007). The final sample size after applying weights and imputing missing data was 11,715 . Variables were chosen from the child health and well-being questionnaire (parent report), the critical family processes questionnaire (parent report), teachers' reports of the child's social skills, and the child's self-report of their internalizing and externalizing behaviors. The parent report variables were observed variables whereas the teacher's report variables and the child's self-report variables were factors as reported in ECLS-K data.

\section{Analysis}

Cronbach's alpha and its confidence interval was computed for each factor and are reported in Table 2. The teacher and child self-report data were continuous factors and the parent report variables were measured on Likert scales or were count data (e.g., number of times in the past week I praised my child). Mardia's coefficient was greater than three for the data. This indicated lack of multivariate normality. Therefore, asymptotic covariance matrix and polychoric correlation matrix were used to correct for non-normality and the ordinal scale of the data, respectively
TABLE 1 | List of observed variables.

\begin{tabular}{|c|c|c|}
\hline Variable name & Time of measurement & $\begin{array}{l}\text { Scale of } \\
\text { measurement }\end{array}$ \\
\hline P1SOCIAL (P1So)* & Kindergarten $(P, F)$ & $\begin{array}{l}\text { 1-Never } \\
\text { 4-Very Often } \\
\text { composite score }\end{array}$ \\
\hline P1SADLON (P1Sa)* & Kindergarten (P, F) & \\
\hline P2SOCIAL (P2So)* & Kindergarten (P, S) & \\
\hline P2SADLON (P2Sa)* & Kindergarten (P, S) & \\
\hline T1EXTERN (T1E) & Kindergarten (T, F) & \\
\hline T1INTERN (T1I) & Kindergarten (T, F) & \\
\hline T2EXTERN (T2E) & Kindergarten $(T, S)$ & \\
\hline T2INTERN (T2I) & Kindergarten $(T, S)$ & \\
\hline P4SOCIAL (P4So)* & 1st Grade (P, S) & \\
\hline P4SADLON (P4Sa) $)^{*}$ & 1st Grade (P, S) & \\
\hline T4EXTERN (T4E) & 1st Grade (T, S) & \\
\hline T4INTERN (T4I) & 1st Grade (T, S) & \\
\hline T5EXTERN (T5E) & 3rd Grade $(T, S)$ & \\
\hline T5INTERN (T5I) & 3rd Grade (T, S) & \\
\hline T6EXTERN (T6E) & 5th Grade $(T, S)$ & \\
\hline T6INTERN (T6I) & 5th Grade $(T, S)$ & \\
\hline C5SDQEXR (C5E) & 3rd Grade (C, S) & $\begin{array}{l}\text { 1-Not at All True } \\
\text { 4-Very True } \\
\text { composite score }\end{array}$ \\
\hline C5SDQINR (C5I) & 3rd Grade (C, S) & \\
\hline C6SDQEXT (C6E) & 5th Grade (C, S) & \\
\hline C6SDQINT (C6I) & 5th Grade (C, S) & \\
\hline C7LOCUS (C7Locus) & 8th Grade (C, S) & \\
\hline C7LONLY (C7Lone) & 8th Grade (C, S) & \\
\hline C7SAD (C7Sad) & 8th Grade (C, S) & \\
\hline P7NUMPRS (P7NPrs) & 8th Grade (P, S) & $\begin{array}{l}\text { How many times } \\
\text { in the past week? }\end{array}$ \\
\hline P7NUMPHY (P7NPhy) & 8th Grade (P, S) & \\
\hline P7NUMLOV (P7NLov) & 8th Grade (P, S) & \\
\hline P7ENJOY (P7Ejy) & 8th Grade (P, S) & $\begin{array}{l}\text { 1-Strongly Agree } \\
\text { 4-Strongly } \\
\text { Disagree }\end{array}$ \\
\hline P7SATPRB (P7Sat) & 8th Grade (P, S) & \\
\hline P7LIFLNG (P7Life) & 8th Grade (P, S) & \\
\hline P7LISTNS (P7Lsn) & 8th Grade (P, S) & \\
\hline P7LOVE (P7Lov) & 8th Grade (P, S) & \\
\hline P7FAITHF (P7 Fait) & 8th Grade (P, S) & \\
\hline P7STPSPK (P7Stp) & 8th Grade (P, S) & \\
\hline P7DSCUSS (P7Dis) & 8th Grade (P, S) & \\
\hline P7COMPRM (P7Cprm) & 8th Grade (P, S) & \\
\hline P7SHOUT (P7Sho) & 8th Grade (P, S) & \\
\hline P7CRITICIZE (P7Cri) & 8th Grade (P, S) & \\
\hline P7ARGUE (P7Arg) & 8th Grade (P, S) & \\
\hline P7BULLID* & 8th Grade $(P, S)$ & $\begin{array}{l}\text { 1-Not True } \\
\text { 3-Certainly True }\end{array}$ \\
\hline
\end{tabular}

Sources are represented by parent $(P)$, teacher $(T)$, and child $(C)$. Semester of measurement is represented by fall (F) and spring (S). The dependent variable is noted in boldface. Variable names in parentheses correspond to the variable names in the figures, which were shortened due to space restriction. ${ }^{*}$ represents measures from SRS. 
(Jöreskog, 1994); robust unweighted least squares estimation was used to fit the model (Forero et al., 2009). Satorra and Bentler's (1988) scaled $\chi^{2}$ statistic is reported, but this statistic was not used to assess model fit because of its well-known sensitivity to sample size. The fit of each model was assessed using: (a) the comparative fit index (CFI) (b) the root-mean-square-error of approximation (RMSEA), its $90 \%$ confidence interval; and (c) the standardized root-mean-square-residual (SRMR). Values of CFI $\geq 0.95, R M S E A \leq 0.05$, and SRMR $\leq 0.08$ were considered indicators of good model fit, and values of $0.05<$ RMSEA $\leq 0.08$ and $0.90 \leq C F I<0.95$ indicated acceptable model fit (Browne and Cudeck, 1993; Hu and Bentler, 1999).

\section{Model}

A measurement model (confirmatory factor analysis, CFA, Figure 1) was fitted to the data followed by a structural equation model (SEM, Figure 2). CFA was used to confirm the underlying factor structure while factors were used to predict other

TABLE 2 | Cronbach's alpha and their confidence intervals, omegas, and composite reliabilities for factors.

\begin{tabular}{|c|c|c|c|c|c|}
\hline Factor & Factor names & $\alpha$ & $95 \% \mathrm{Cl}$ & Omega & $\begin{array}{c}\text { Composite } \\
\text { Reliability }\end{array}$ \\
\hline PResp & Parental responsiveness & 0.82 & {$[0.81,0.82]$} & 0.87 & 0.82 \\
\hline PMardiss & Parents' marital dissatisfaction & 0.88 & {$[0.87,0.88]$} & 0.90 & 0.95 \\
\hline PPasscomm & Parents' passive communication & 0.52 & {$[0.50,0.53]$} & 0.59 & 0.69 \\
\hline TExtern & Teachers' report of externalizing behaviors & 0.86 & {$[0.85,0.86]$} & 0.90 & 0.87 \\
\hline TIntern & Teachers' report of internalizing behaviors & 0.68 & {$[0.67,0.69]$} & 0.72 & 0.68 \\
\hline PSocial & Parents' report of externalizing behaviors & 0.76 & {$[0.75,0.77]$} & 0.78 & 0.74 \\
\hline PSad & Parents' report of internalizing behaviors & 0.71 & {$[0.70,0.72]$} & 0.74 & 0.70 \\
\hline CExtern & Child's self-report of externalizing behaviors & 0.69 & {$[0.68,0.70]$} & 0.72 & 0.70 \\
\hline Clntern & Child's self-report of internalizing behaviors & 0.78 & {$[0.77,0.78]$} & 0.80 & 0.76 \\
\hline
\end{tabular}
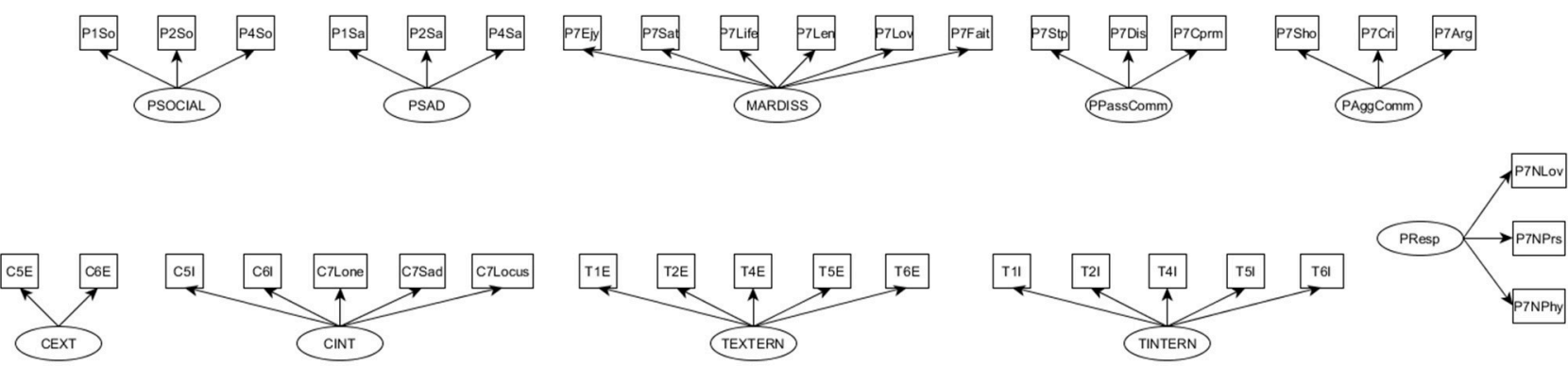

FIGURE 1 | Measurement model. All factors were correlated. Factor correlations and error variances are not shown.

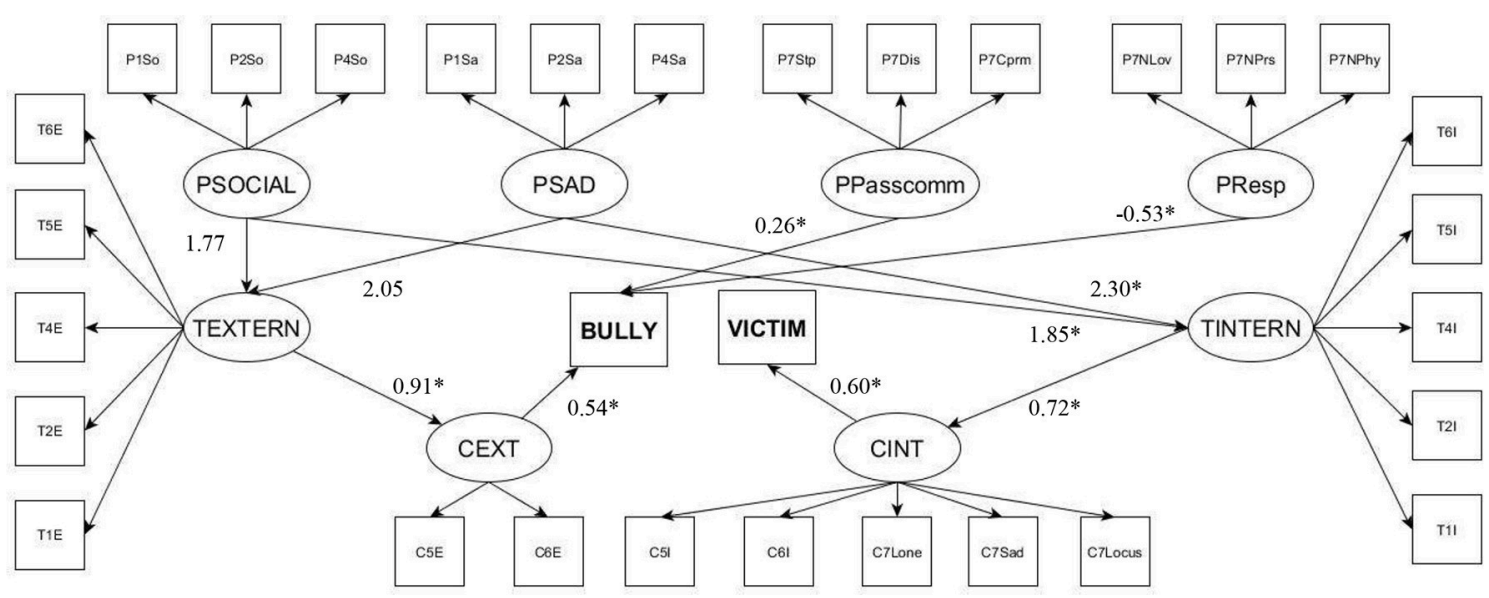

FIGURE 2 | Final structural equation model. Error variances are not shown. 
factors using SEM (i.e., directional relationships). The factors in the CFA model included parent reports of marital aggressive communication (PAggcomm), marital passive communication (PPasscomm), level of parental responsiveness (PResp) all at time-point 7, and their reports of the child's use of social skills and feelings of sadness or loneliness (PSad, measured using indicators at time-points 1, 2, and 4). The CFA model also included teacher reports of the child's externalizing (TExtern) and internalizing behaviors (TIntern) measured using indicators at time-points 1 , 2, 4, 5, and 6 and the child's self-report of externalizing (CExtern) and internalizing behaviors (CIntern) measured using indicators at time-points 5,6 , and 7 .

In the CFA model, the factor called marital dissatisfaction (PMardiss) indicates a negative variable because although the items that indicate it are positively worded, the scale of measurement is increasingly negative (1 - strongly agree, 4 - strongly disagree). Similarly, passive communication (PPasscomm) and aggressive communication (PAggcomm) factors are negatively worded because their indicator variables are measured on a negative scale ( 1 - never, 4 - often). Although it is desirable that each factor be indicated by at least 3 variables, child externalizing behavior (CExtern) was indicated by only two variables (from times T5 and T6) because of high multicollinearity with other possible indicator variables. All factors were allowed to correlate freely. Factor correlations are not indicated in Figure 1 to help visual clarity.

The SEM tested several research hypotheses: (a) parent reports of a child's social skills and experiencing feelings of sadness and loneliness (PSocial, PSad) at T1, T2, and T4 predict the child's bullying and victim status in the 8 th grade (i.e., T8; BULLY, VICTIM); (b) teacher reports of internalizing (TIntern) and externalizing behaviors (TExtern) of the child at T1, T2, T4, T5, and T6 and child self-reports at T5, T6, and T7 (CIntern and CExtern) predict the child's bullying and victim status at T8; (c) children with parents who reported both higher levels of marital dissatisfaction (PMardiss) and aggressive marital communication (PAggcomm), lower levels of passive marital communication (PPasscomm) with their partner, and lower levels of responsiveness (PResp) toward their child at T1, T2, T4, and T7 have higher probabilities of being bullies at T8; and (d) children with parents who reported higher levels of marital dissatisfaction (PMardiss) with their partner as well as higher levels of responsiveness (PResp) toward their child have higher probabilities of being victims of bullying at T8. Bullying and victim statuses were based on parent reports.

\section{RESULTS}

Cronbach's internal consistency $\alpha$ and its 95\% confidence interval are reported for each factor in Table 1. Because most factors had few items and because $\alpha$ increases with the number of items, these values are presented as an indication of the correlation between the items but the values are not interpreted. The CFA model had good model fit $\left(\chi_{S B}^{2}=21412, d f=612, C F I=0.95, R M S E A=\right.$ 0.054, RMSEA 90\% CI $[0.053,0.054], S R M R=0.046)$. Correlations between the factors ranged from 0.76 to -0.41 . The absolute value of all standardized factor pattern coefficients were higher than 0.4 , which indicates support for convergent validity. The direction of the relationship between the factors were as expected from previous research. Therefore, this model was retained. Factor correlations are reported in Table 3. The standardized factor pattern coefficients and structure coefficients are reported along with average variance extracted in Table 4. The low magnitude of structure coefficients indicates support for discriminant validity with few relatively large values. For example the structure coefficients passive communication (PPasscomm) items have low but not negligible structure coefficients on marital dissatisfaction (PMardiss). However, these values are to be expected because passive communication (PPasscomm) and marital dissatisfaction (PMardiss) can be expected to have high correlation. The non-negligible structure coefficients are

TABLE 3 | Correlation matrix of factors.

\begin{tabular}{|c|c|c|c|c|c|c|c|c|c|c|c|c|}
\hline Variable & 1 & 2 & 3 & 4 & 5 & 6 & 7 & 8 & 9 & 10 & 11 & 12 \\
\hline 1. PResp & & -0.16 & -0.16 & -0.06 & -0.03 & 0.01 & 0.21 & -0.01 & -0.09 & 0.07 & -0.09 & -0.05 \\
\hline 2. PMardiss & & & 0.76 & 0.41 & 0.10 & 0.06 & -0.22 & 0.15 & 0.24 & 0.04 & 0.17 & 0.13 \\
\hline 3. PPasscomm & & & & 0.62 & 0.08 & -0.03 & -0.15 & 0.17 & 0.37 & 0.11 & 0.18 & 0.08 \\
\hline 4. PAggcomm & & & & & 0.01 & 0.01 & -0.04 & 0.04 & 0.17 & 0.01 & 0.01 & 0.01 \\
\hline 5. TExtern & & & & & & 0.50 & -0.12 & 0.20 & 0.46 & 0.35 & 0.64 & 0.29 \\
\hline 6. TIntern & & & & & & & -0.27 & 0.32 & 0.26 & 0.41 & 0.38 & 0.40 \\
\hline 7. PSocial & & & & & & & & -0.41 & -0.16 & -0.11 & -0.13 & -0.17 \\
\hline 8. PSad & & & & & & & & & 0.29 & 0.31 & 0.15 & 0.23 \\
\hline 9. BULLY & & & & & & & & & & 0.48 & 0.40 & 0.33 \\
\hline 10. VICTIM & & & & & & & & & & & 0.29 & 0.37 \\
\hline 11. CExtern & & & & & & & & & & & & 0.6 \\
\hline 12. CIntern & & & & & & & & & & & & \\
\hline
\end{tabular}

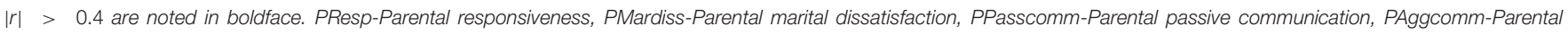

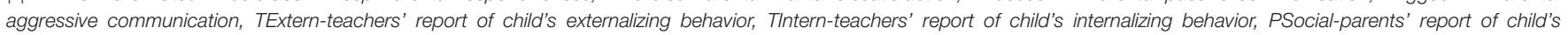

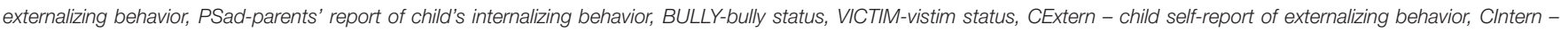
child self-report of internalizing behavior. 
TABLE 4 | Standardized factor pattern and structural coefficients of factors.

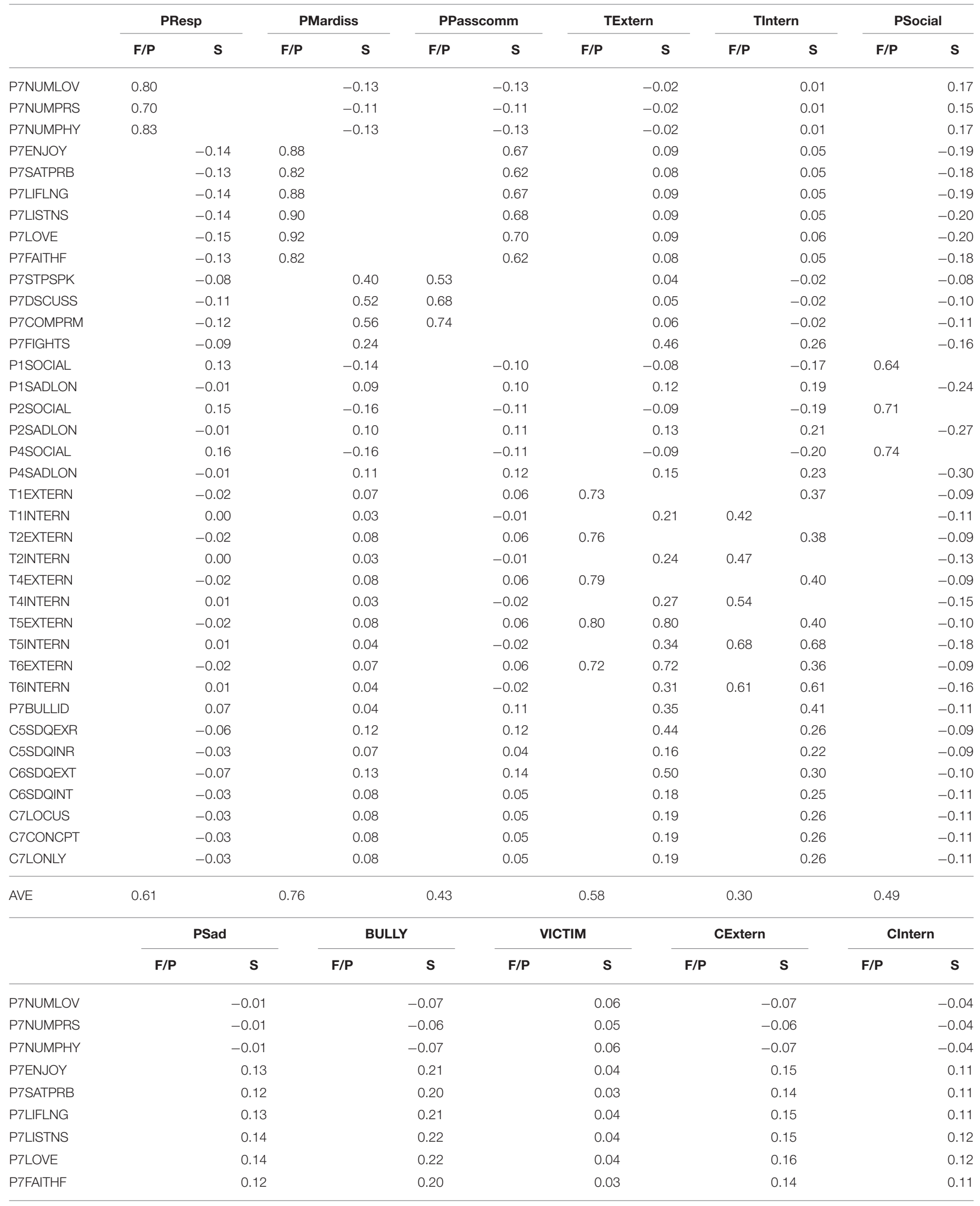


TABLE 4 | Continued

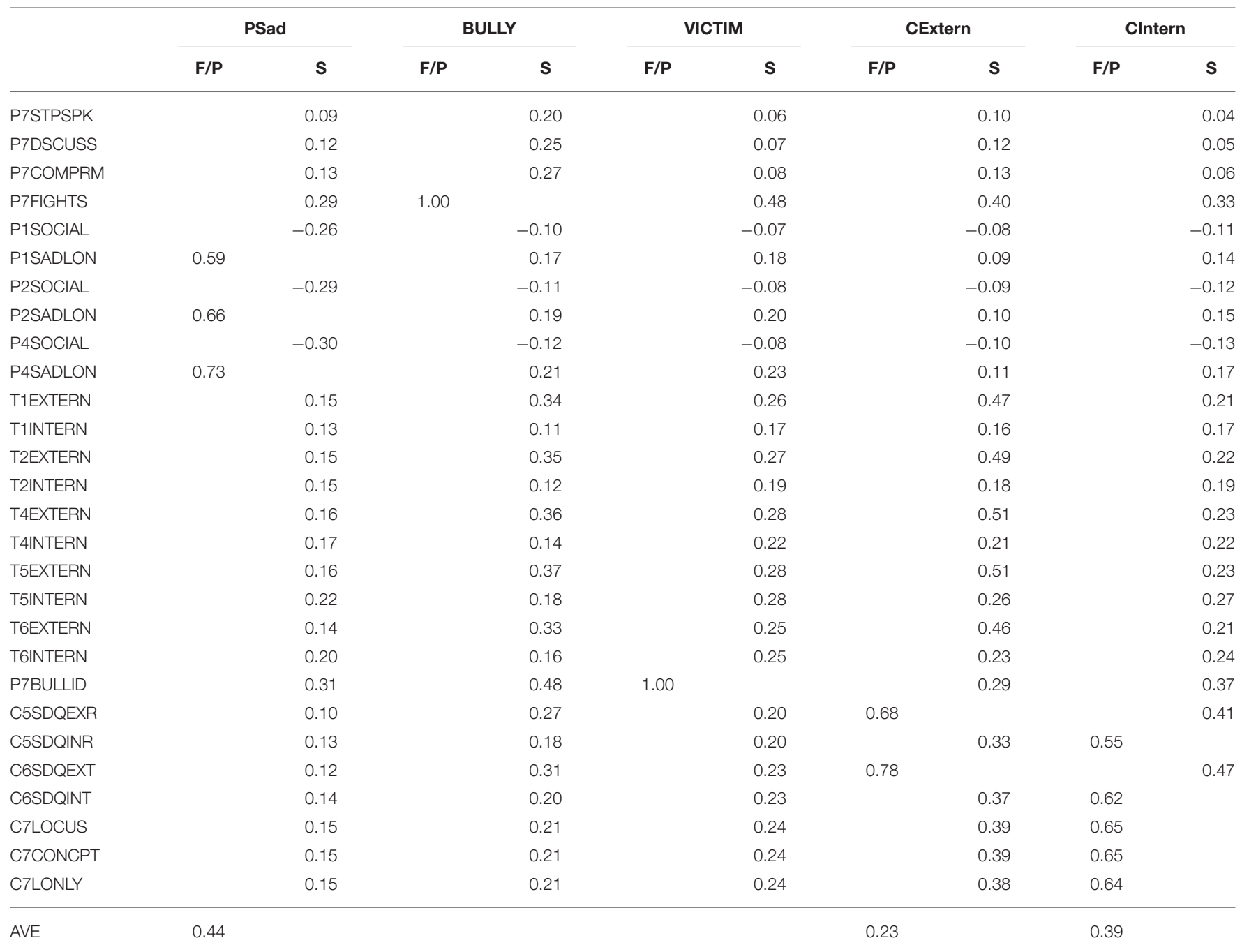

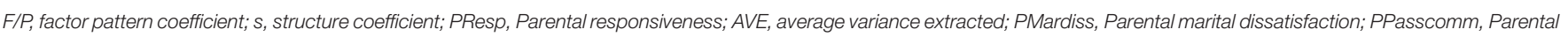

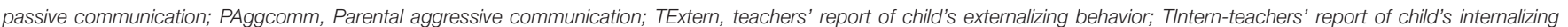

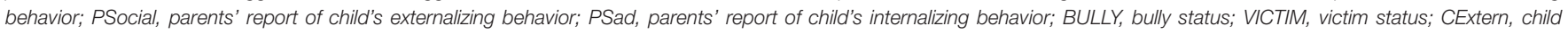

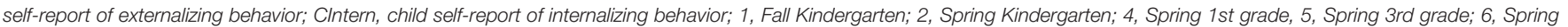
5th grade; 7, Spring 8th grade; $C$, child report; $P$, parent report; $T$, teacher report.

therefore not considered a threat to discriminant validity (Shaffer et al., 2016). The average variance extracted is expected to be higher than the squared structure coefficient of any other item on the factor in order to support discriminant validity. With the exception of T5Intern and T6Intern there was support for discriminant validity.

Initially, marital dissatisfaction (PMardiss) and aggressive communication (PAggcomm) were predictors of passive communication (PPasscomm). These paths were removed due to multicollinearity. The final SEM after removing these paths had adequate model fit $\left(\chi_{S B}^{2}=27302.44, d f=646, C F I=\right.$ 0.93, RMSEA $=0.059$, RMSEA 90\% CI $[0.059,0.060]$, SRMR = 0.062 ). The final structural equations that were retained and their respective unstandardized coefficients, standard errors, and $R^{2}$ values are reported in Table 5. Parents' report of the child's externalizing (PSocial) and internalizing (PSad) behaviors from T1-T4 predicted teachers' report (TExtern) of the child's externalizing behavior T1-T6. This, in turn, predicted the child's self-report of externalizing behavior (CExtern) from T5 and T6. Child's externalizing behavior (CExtern) was a statistically significant predictor of bullying at $\mathrm{T} 7$ and had a medium-large effect size $(\beta=0.57)$. TExtern was a complete mediator of the effect between parents' report of the child's externalizing (PSocial) and internalizing behaviors (PSad), and the child's self-report of the child's externalizing behavior (CExtern).

Similarly, parents' report of the child's externalizing (PSocial) and internalizing (PSad) behaviors from T1-T4 predicted teachers' report (TIntern) of the child's internalizing behavior T1T6. This, in turn, predicted the child's self-report of internalizing behavior (CIntern) from T5 and T6. Child's internalizing behavior (CIntern) was a statistically significant predictor of being a victim of bullying at T7 and had a medium-large 
TABLE 5 | Structural equations and their unstandardized regression coefficients.

\begin{tabular}{|c|c|c|c|c|c|}
\hline DV & & IV1 & IV2 & IV3 & $\mathrm{R}^{2}$ \\
\hline PAggcomm & $=$ & -0.43PMardiss & 1.06PPasscomm & & 0.57 \\
\hline SE & & 0.094 & 0.046 & & \\
\hline TExtern & $=$ & 1.99PSocial & 2.27PSad & & 0.64 \\
\hline SE & & 1.83 & 1.77 & & \\
\hline TIntern & $=$ & 1.86PSocial & 2.30PSad & & 0.72 \\
\hline SE & & 0.82 & 0.83 & & \\
\hline CExtern & $=$ & 0.94TExtern & & & 0.87 \\
\hline SE & & 0.02 & & & \\
\hline CIntern & $=$ & 0.66TIntern & & & 0.43 \\
\hline SE & & 0.29 & & & \\
\hline BULLY & $=$ & 0.27PAggcomm & 0.57CExtern & $-0.1 P R e s p$ & 0.42 \\
\hline SE & & 0.04 & 0.1 & 0.01 & \\
\hline VICTIM & $=$ & 0.57 Clntern & & & 0.32 \\
\hline SE & & 0.14 & & & \\
\hline
\end{tabular}

SE, standard error; DV, Dependent variable; IV, Independent variable; PResp, Parental responsiveness; PMardiss, Parental marital dissatisfaction; PPasscomm, Parental passive communication; PAggcomm, Parental aggressive communication; TExtern, teachers' report of child's externalizing behavior; TIntern, teachers' report of child's internalizing behavior; PSocial, parents' report of child's externalizing behavior; PSad, parents' report of child's internalizing behavior; BULLY-bully status; VICTIM, vistim status; CExtern, child self-report of externalizing behavior; CIntern, child self-report of internalizing behavior.

effect size $(\beta=0.57)$. Teachers' report of internalizing behavior (TIntern) was a complete mediator of the effect between parents' report of the child's externalizing (PSocial) and internalizing behaviors (PSad), and the child's self-report of the child's internalizing behavior (CIntern). Child's self-report of externalizing behavior (CExtern) was highly correlated with teachers' report $(r=0.92)$. But child's self-report of internalizing behavior (CIntern) was not as highly correlated with teachers' report (TIntern, $r=0.65$ ). Parent's responsiveness to the child (PResp) was not a statistically significant predictor of any of the other factors. Passive communication (PPasscomm) between parents predicted future bullying to some degree $(\beta=0.28)$ but not the future victim status $(\beta=0.04)$.

\section{DISCUSSION}

The results of the present study were able to confirm the hypothesis governing the current research; that is, parent, teacher, and student reports of internalizing behaviors were able to predict victim status at Grade 8, while reports of externalizing behaviors, as well as parental reports of marital and home characteristics were able to predict bully status at Grade 8 . Additionally, parent reports of externalizing, and internalizing behaviors were found to predict teachers and students reports of the behaviors, demonstrating reliability in the data from three separate reporters across seven data collection points. These results provide evidence that utilizing readily available information regarding students, like that included in large data sets like the ECLS-K, is one possible avenue toward identifying those children at risk for becoming bullies and victims, and potentially intervening early in these childrens' lives.
The results indicated that while externalizing behaviors, as reported by teachers in kindergarten, 1st, 3rd, and 5th grades, predicted nearly $90 \%$ of the variance in child-reported externalizing behaviors, teacher reports of internalizing behaviors predicted less than half of the variance in child-reported internalizing behaviors. This discrepancy may be due to the nature of these types of behaviors. Externalizing behaviors draw attention to the child and his or her behaviors, making it easier for teachers and parents to recognize potential issues. Internalizing behaviors are by their very nature internal and, therefore, more difficult to detect; this makes teacher and parent reports of internalizing behaviors less reliable than their externalizing counterparts. Future researchers may consider including validated measures of internalizing behaviors to overcome the difficulty parents and teachers face in recognizing the onset and development of these internalizing behaviors.

While the current study provided support for a growing body of evidence that bullies experience less supportive home environments (Lereya et al., 2013; see Espelage et al., 2018), no such support was found for their victim counterparts. While bullies report less parental responsiveness and communication and harsher forms of punishment, victims can experience anything from abuse and neglect (Lereya et al., 2013) to overly responsive parenting, especially for male victims (Finnegan et al., 1998; Ladd and Kochenderfer-Ladd, 1998; Georgiou, 2008; Reavis et al., 2010). This wide variation in characteristics may make predicting victim status more difficult than bully status, especially when relying upon information that teachers and administrators would have readily available. This makes the correct identification of internalizing behaviors all the more important, as family characteristics may not serve as reliable predictors of victim status.

As with any analysis of this kind, the present study was restricted by a number of limitations. Firstly, the present analysis was limited by the scope of questions presented by the questionnaires created for the ECLS-K. Despite asking specific questions regarding bullying and victimization behaviors, the ECLS-K relied upon only parental reports of bullying and victimization in Grade 8. This could be problematic, as Georgiou and Stavrinides (2013) reported a negative correlation between child disclosure and both bully and victim statuses. This discrepancy indicates children involved in these behaviors may be less likely to confide in their parents after bullying or victimization occurs, and as parents are not present at school to witness the behaviors, may not be aware that the bullying is taking place.

Similarly, questions regarding the family environment may have been limited by the scale of measurement, and as such may not have been able to distinguish between appropriate levels of responsiveness and overly-responsive parenting. The ECLS-K questions regarding responsiveness asked for responses regarding the number of times parents stated that they loved or otherwise responded to the child rather than the quality of those interactions. While professions of love and affection may occur regularly, the context in which those professions are made may counteract the statements. Additionally, the reliance on only parental reports of family functioning may have been 
problematic, as parents may feel pressure to downplay marital conflict or use of corporal punishment on questionnaires that may be seen by school administrators or other officials. Future research would benefit from gathering more detail regarding these interactions from multiple sources in order to better account for the variability between bullies' and victims' home lives.

Despite the limitations associated with this analysis, the use of the ECLS-K allowed for the use of data from three reporters to predict bully and victim statuses across seven collection points. This represents best practice as it involves utilizing multiple sources to correctly identify bullies and victims (Ladd and Kochenderfer-Ladd, 2002). The ECLS-K also offered the opportunity to investigate variables that are readily accessible to teachers and other school personnel on a daily basis from a large, nationally-representative data set. For future intervention efforts, providing teachers with basic training regarding the identification of externalizing and internalizing behaviors, as well as home and environmental characteristics could help teachers to identify the children most in need of targeted interventions. This would then allow teachers the ability to refer these children for services much like the referrals they already perform on a regular basis for learning disabilities and other behavioral issues.

As this analysis has shown, it is possible for both parents and teachers to identify children at risk for becoming bullies and victims early in development. Identifying children at risk as early as kindergarten and 1st grade, then providing interventions

\section{REFERENCES}

Ahn, H-J., Rodkin, P. C., and Gest, S. (2013). Teacher-student agreement on "bullies and kids they pick on" in elementary school classrooms: gender and grade differences. Theor. Pract. 52, 257-263. doi: 10.1080/00405841.2013.829728

Baldry, A. C., and Farrington, D. P. (2000). Bullies and delinquents: personal characteristics and parenting styles. J. Commun. Appl. Soc. Psychol. 10, 17-31. doi: 10.1002/(SICI) 1099-1298(200001/02)10:1 < 17::AID-CASP526>3.0.COf-M

Braithwait, S. R., Steele, E., Spjut, K., Dowdle, K., and Harper, J. (2015). Parent-child connectedness mediates the association between marital conflict and children's internalizing/externalzing outcomes. J. Child Family Stud. 24, 3690-3699. doi: 10.1007/s10826-015-0177-8

Browne, M. W., and Cudeck, R. (1993). "Alternative ways of assessing model fit," in Testing Structural Equation Models eds K. A. Bollen and J. S. Long (Beverly Hills, CA: Sage), 136-162.

Cassidy, T. (2009). Bullying and victimization in school children: the role of social identity, problem-solving style, and family and school context. Soc. Psychol. Educ. 12, 63-76. doi: 10.1007/s11218-008-9066-y

Charalampous, K., Demetriou, C., Tricha, L., Ioannou, M., Georgiou, S., Nikiforou, M., et al. (2018). The effect of parental style on bullying and cyber bullying behaviors and the mediating role of peer attachment relationships: a longitudinal study. J. Adolesc. 64, 109-123. doi: 10.1016/j.adolescence.2018.02.003

Cook, C. R., Williams, K. R., Guerra, N. G., Kim, T. E., and Sadek, S. (2010). Predictors of bullying and victimization in childhood and adolescence: a meta-analytic investigation. Sch. Psychol. Q. 25, 65-83. doi: 10.1037/a0020149

Cui, M., Donnellan, M. B., and Conger, R. D. (2007). Reciprocal influences between parents' marital problems and adolescent internalizing and externalizing behavior. Dev. Psychol. 43, 1544-1552. doi: 10.1037/0012-1649.43.6.1544 aimed at improving family functioning in the home and the child's functioning at school may lower the risk for ultimate victimization or aggressive behaviors. Considering that over onefifth of American children report being bullied within a single school year (U.S. Department of Education Institute of Education Science National Center for Educational Statistics, 2016), early identification of children at risk for victimization and bullying may be the key to stopping such behaviors before they begin. Although several programs are currently geared toward stopping current bullying in the schools, these groups may fail to recognize the contributions of the home environment and, perhaps more importantly, long-term developmental trajectories leading to the behaviors they are working to prevent.

\section{ETHICS STATEMENT}

The data are obtained from the national database called Early Childhood Longitudinal Study (ECLS). Permission was obtained from the NCES to use this dataset.

\section{AUTHOR CONTRIBUTIONS}

MM wrote the background, literature review, and the conclusion sections. PN conducted the data analysis, wrote the methods and results section, and responded to the reviewers' comments. RG wrote the conclusion section. All authors contributed to the substantive reason behind the model fitted.

Dehue, F., Bolman, C., Vollink, T., and Pouwelse, M. (2012). Cyberbullying and traditional bullying in relation to adolescents' perception of parenting. $J$. CyberTher. Rehabil. 5, 25-34.

Doty, J. L., Gower, A. L., Rudi, J. H., McMorris, B. J., and Borowsky, I. W. (2017). Patterns of bullying and sexual harassment: connections with parents and teachers as direct protective factors. J. Youth Adolesc. 46, 2289-2304. doi: 10.1007/s10964-017-0698-0

Eastman, M., Foshee, V., Ennett, S., Sotres-Alvarez, D., McNaughton Reyes, H. L., Faris, R., et al. (2018). Profiles of internalizing and externalizing symptoms associated with bullying victimization. J. Adolesc. 65, 101-110. doi: 10.1016/j.adolescence.2018.03.007

Elliot, M., and Cornell, D. G. (2009). Bullying in middle school as a function of insecure attachment and aggressive attitudes. Sch. Psychol. Int. 30, 201-214. doi: $10.1177 / 0143034309104148$

Espelage, D. L., Van Ryzin, M. J., and Holt, M. K. (2018). Trajectories of bully perpetration across early adolescence: static risk factors, dynamic covariates, and longitudinal outcomes. Psychol. Viol. 8, 141-150. doi: 10.1037/vio0000095

Finnegan, R. A., Hodges, E. V. E., and Perry, D. G. (1998). Victimization by peers: associations with children's reports of mother-child interaction. J. Person. Soc. Psychol. 75, 1076-1086. doi: 10.1037/0022-3514.75.4.1076

Flouri, E., and Buchanan, A. (2003). The role of mother involvement and father involvement in adolescent bullying behavior. J. Int. Viol. 18, 634-644. doi: $10.1177 / 0886260503251129$

Forero, C. G., Maydeu-Olivares, A., and Gallardo-Pujol, D. (2009). Factor analysis with ordinal indicators: a monte carlo study comparing DWLS and ULS estimation. Struct. Equat. Model. 16, 625-641. doi: 10.1080/10705510903203573

Georgiou, S. N. (2008). Parental style and child bullying and victimization experiences at school. Soc. Psychol. Educ. 11, 213-227. doi: 10.1007/s11218-007-9048-5 
Georgiou, S. N. (2009). Personal and maternal parameters of peer violence at school. J. Sch. Viol. 8, 100-119. doi: 10.1080/153882208020 73928

Georgiou, S. N., Ioannou, M., and Stavrinides, P. (2018). Cultural values as mediators between parenting style and bullying behavior at school. Soc. Psychol. Educ. 21, 27-50. doi: 10.1007/s11218-017-9413-y

Georgiou, S. N., and Stavrinides, P. (2013). Parenting at home and bullying at school. Soc. Psychol. Educ. 16, 165-179. doi: 10.1007/s11218-012-9209-z

Gersham, F. M., and Elliot, S. N. (1990). Social Skills Rating System. Circle Pines, $\mathrm{MN}$ : American Guidance Service.

Gomez-Ortiz, O., Romera, E. M., and Ortega-Ruiz, R. (2016). Parenting style and bullying. The mediating role of parental psychological aggression and physical punishment. Child Abuse Neglect 51, 132-143. doi: 10.1016/j.chiabu.2015.10.025

Harold, G. T., Osborne, L. N., and Conger, R. D. (1997). Mom and dad are at it again: adolescent perceptions of marital conflict and adolescent psychological distress. Dev. Psychol. 33, 333-350. doi: 10.1037/0012-1649.33.2.333

Hawker, D. S. J., and Boulton, M. J. (2000). Twenty years' research on peer victimization and psychosocial maladjustment: a meta-analytic review of cross-sectional studies. J. Child Psychol. Psychiatry 41, 441-455. doi: 10.1111/1469-7610.00629

Haynie, D. L., Nansel, T., Eitel, P., Crump, A. D., Saylor, K., Yu, K., et al. (2001). Bullies, victims, and bully/victims: distinct groups of at-risk youth. J. Early Adolesc. 21, 29-49. doi: 10.1177/0272431601021001002

Holt, M. K., and Espelage, D. L. (2007). Perceived social support among bullies, victims, and bully-victims. J. Youth Adolesc. 36, 984-994. doi: 10.1007/s10964-006-9153-3

Hu, L.-T., and Bentler, P. M. (1999). Cutoff criteria for fit indexes in covariance structure analysis: conventional criteria versus new alternatives. Struct. Equat. Model. 6, 1-55. doi: 10.1080/10705519909540118

Hwang, S., Kim, Y. S., Koh, Y.-J., Bishop, S., and Leventhal, B. L. (2017). Discrepancy in perception of bullying experiences and later internalizing and externalizing behavior: a prospective study. Aggress. Behav 37, 193-206. doi: $10.1002 / \mathrm{ab} .21707$

Jöreskog, K. G. (1994). On the estimation of polychoric correlations and their asymptotic covariance matrix. Psychometrika 59, 381-389. doi: 10.1007/BF02296131

Jöreskog, K. G., and Sörbom, D. (2007). LISREL 8.8 [Computer software]. Lincolnwood, IL: Scientific Software International, Inc.

Keelan, C. M., Schenk, A. M., McNally, M. R., and Fremouw, W. J. (2014). The interpersonal worlds of bullies: parents, peers, partners. J. Interpers. Viol. 29, 1338-1353. doi: 10.1177/0886260513506278

Kozasa, S., Oiji, A., Kiyota, A., Sawa, T., and Kim, S.-Y. (2017). Relationship between the experience of being a bully/victim and mental health in preadolescene and adolescence: a cross-sectional study. Ann. Gen. Psychiatry 16:37. doi: 10.1186/s12991-017-0160-4

Kretschmer, T., Sentse, M., Meeus, W., Verhulst, F. C., Veenstra, R., and Oldehinkel, A. J. (2016). Configurations of adolescents' peer experiences: associations with parent-child relationship quality and parental problem behavior. J. Res. Adolesc. 26, 474-491. doi: 10.1111/jora.12206

Ladd, G. W., and Kochenderfer-Ladd, B. (1998). Parenting behaviors and parentchild relationships: correlates of peer victimization in kindergarten? Dev. Psychol. 34, 1450-1458. doi: 10.1037/0012-1649.34.6.1450

Ladd, G. W., and Kochenderfer-Ladd, B. (2002). Identifying victims of peer aggression from early to middle childhood: analysis of cross-informant data for concordance, estimation of relational adjustment, prevalence of victimization, and characteristics of identified victims. Psychol. Assess. 14, 74-96. doi: 10.1037//1040-3590.14.1.74

Lereya, S. T., Copeland, W. E., Costello, E. J., and Wolke, D. (2015a). Adult mental health consequences of peer bullying and maltreatment in childhood: two cohorts in two countries. Lancet Psychiatry. 2, 524-531. doi: 10.1016/S2215-0366(15)00165-0

Lereya, S. T., Copeland, W. E., Zammit, S., and Wolke, D. (2015b). Bully/victims: a longitudinal, population-based cohort study of their mental health. Eur. J. Child Adolesc. Psychiatry 24, 1461-1471. doi: 10.1007/s00787-015-0705-5
Lereya, S. T., Samara, M., and Wolke, D. (2013). Parenting behavior and the risk of becoming a victim and a bully/victim: a meta-analysis study. Child Abuse Neglect 37, 1091-1108. doi: 10.106/j.chiabu.2013.03.001

Mohr, A. (2006). Family variables associated with peer victimization: does family violence enhance the probability of being victimized by peers? Swiss J. Psychol. 65, 107-116. doi: 10.1024/1421-0185.65.2.107

Pacer Center (2016). National Bullying Prevention Month. Available online at: http://www.pacer.org/bullying/nbpm/

Pepler, D., Jiang, D., Craig, W., and Connolly, J. (2008). Developmental trajectories of bullying and associated factors. Child Dev. 79, 325-338. doi: 10.1111/j.1467-8624.2007.01128.x

Reavis, R. D., Keane, S. P., and Calkins, S. D. (2010). Trajectories of peer victimization: the role of multiple relationships. Merrill Palmer Q. 56, 303-332. doi: $10.1353 / \mathrm{mpq} .0 .0055$

Satorra, A., and Bentler, P. M. (1988). "Scaling correlations for chi-square statistics in covariance structure analysis," in Proceedings of the Business and Economic Statistics Section of the American Statistical Association, 308-313. Available online at: https://escholarship.org/uc/item/8dv7p2hr

Shaffer, J. A., DeGeest, D. S., and Li, A. (2016). Tackling the problem of construct proliferation: a guide for assessing the discriminant validity of conceptually related constructs. Organ. Res. Methods 19, 80-110. doi: $10.1177 / 1094428115598239$

Stevens, V., De Bourdeaudhuij, I., and Van Oost, P. (2002). Relationship of the family environment to children's involvement in bully/victim problems at school. J. Youth Adolesc. 31, 419-428. doi: 10.1023/A:1020207003027

Stockdale, M. S., Hangaduambo, S., Duys, D., Larson, K., and Sarvela, P. D. (2002). Rural elementary students', parents', and teachers' perceptions of bullying. Am. J. Health Behav. 26, 266-277. doi: 10.5993/AJHB.26.4.3

Stomp Out Bullying (2016). Blue Shirt Day World Day Of Bullying Prevention. Available online at: http://www.stompoutbullying.org/index.php/campaigns/ blue-shirt-day-world-day-bullying-prevention/

Temkin, D. (2015). All 50 States Now Have a Bullying Law. Now What? [Blog post]. Available online at: http://www.huffingtonpost.com/deborah-temkin/all50-states-now-have-a_b_7153114.html

U.S. Department of Education Institute of Education Science National Center for Educational Statistics (2016). Student Reports of Bullying: Results From the 2015 School Crime Supplement to the National Crime Victimization Survey (NCES 2017-015). Available online at: https://nces.ed.gov/pubs2017/2017015.pdf

Veenstra, R., Lindenberg, S., Oldehinkel, A. J., De Winter, A. F., Verhulst, F. C., and Ormel, J. (2005). Bullying and victimization in elementary schools: a comparison of bullies, victims, bully/victims, and uninvolved preadolescents. Dev. Psychol. 41, 672-682. doi: 10.1037/0012-1649.41.4.672

Waasdorp, T. E., and Bradshaw, C. P. (2009). Child and parent perceptions of relational aggression within urban predominately african american children's friendships: examining patterns of concordance. J. Child Fam. Stud. 18, 731-745. doi: 10.1007/s10826-009-9279-5

Waasdorp, T. E., Pas, E. T., O'Brennan, L. M., and Bradshaw, C. P. (2011). A multilevel perspective on the climate of bullying: discrepancies among students, school staff, and parents. J. Sch. Violence 10, 115-132. doi: $10.1080 / 15388220.2010 .539164$

Conflict of Interest Statement: The reviewer RN declared a past collaboration with one of the authors, PN, to the handling Editor.

The remaining authors declare that the research was conducted in the absence of any commercial or financial relationships that could be construed as a potential conflict of interest.

Copyright (c) 2018 Natesan, Mitchell and Glover. This is an open-access article distributed under the terms of the Creative Commons Attribution License (CC BY). The use, distribution or reproduction in other forums is permitted, provided the original author(s) and the copyright owner(s) are credited and that the original publication in this journal is cited, in accordance with accepted academic practice. No use, distribution or reproduction is permitted which does not comply with these terms. 